\title{
An overview of analgesics - anticonvulsants, antidepressants, and other medications (Part 3)
}

\author{
R van Rensburg, H Reuter
}

\section{Division of Clinical Pharmacology, Department of Medicine, Faculty of Medicine and Health Sciences, Stellenbosch University, Cape Town, South Africa}

Corresponding author: rolandmed@gmail.com

Pain is classified by various descriptions. Chronic pain has been described as being neuropathic (due to nervous system lesions), nociceptive (due to tissue damage), or mixed (a combination of neuropathic and nociceptive). The addition of the term nociplastic pain is used to describe patients who experience chronic pain without tissue damage or nervous system lesions. Chronic pain is often difficult to manage, particularly neuropathic pain. Evidence-based pharmacological treatment options include anticonvulsants and antidepressants. The choice of medication will depend on various factors, including patient profile, type of pain, and associated conditions. Medications with the best evidence of efficacy for first-line use in neuropathic pain are the gabapentinoids, carbamazepine, the tricyclic antidepressants, and the serotonin-noradrenaline reuptake inhibitors duloxetine and venlafaxine. The cannabinoids and ketamine are being actively investigated for use in chronic pain. Currently the cannabinoids' potential benefit is outweighed by the adverse effects, and recommendations for the use of ketamine is limited by its parenteral route of administration and low evidence of efficacy in chronic pain.

Keywords: Neuropathic pain, anticonvulsants, antidepressants, evidence-based, cannabinoids

\section{Introduction}

Part 1 of this series discussed NSAIDs, paracetamol, and topical analgesics as the treatment classes of choice for predominantly mild-to-moderate acute pain. Part 2 considered the use of opioids and the atypical opioids, tramadol and tapentadol, for mainly moderate-to-severe nociceptive pain. Part 3 explores the mechanisms of action and place in therapy of the anticonvulsants and antidepressants in neuropathic and other chronic pain management, and will briefly discuss other notable analgesics for this indication.

Pain was previously functionally classified as either nociceptive or neuropathic. Nociceptive pain is defined as "pain that arises from actual or threatened damage to non-neural tissue and is due to the activation of nociceptors."1 A normally functioning somatosensory nervous system is implied in this definition. Conversely, neuropathic pain is succinctly defined as "pain caused by a lesion or disease of the somatosensory nervous system." ${ }^{11}$ There are several causes of neuropathic pain, and it can arise from the central or peripheral nervous system. Common causes include painful diabetic neuropathy, postherpetic neuralgia, HIV neuropathy, and stroke. Patients exhibiting features of both nociceptive and neuropathic pain were regarded as having "mixed pain".

The binary classification of pain was subsequently challenged, as it leaves patients unclassified who do not have both non-neural tissue damage or nervous system lesions. ${ }^{2}$ The designation "nociplastic pain" was introduced for these groups, and is defined as "pain that arises from altered nociception despite no clear evidence of actual or threatened tissue damage causing the activation of peripheral nociceptors, or evidence for disease or lesions of the somatosensory system causing the pain."1 Subsequently, patients with fibromyalgia, complex regional pain syndrome, or irritable bowel syndrome are better described as having predominantly nociplastic pain.

The lack of a clear aetiology in nociplastic pain conditions often make the management of the pain - and the frequently associated comorbidities - difficult and complex. Yet an identifiable aetiology, such as in nociceptive or neuropathic pain, does not guarantee adequate and easily attainable pain control. For example, it has been suggested that more than half of patients with neuropathic pain will not respond to single drug therapy. ${ }^{3}$ Clinical implementation of the findings of studies assessing drugs for neuropathic pain is therefore challenging, because most of the trials were conducted with single drugs. As many patients will likely require combination drug therapy, the paucity of head-to-head studies of combinations necessitate that comparisons of combinations be made on relative response rates of individual drugs. This approach is often inaccurate, and these studies are generally too short for a comprehensive assessment of efficacy in chronic pain (generally 6-8 weeks). ${ }^{4}$ Nevertheless, the anticonvulsants and antidepressants are considered first-line therapy for neuropathic pain, as endorsed by several pain societies. ${ }^{5}$

\section{Anticonvulsants}

\section{Mechanism of action}

The management of neuropathic pain was initially approached according to perceived aetiology, but better understanding of the underlying pathophysiology led to a more mechanistic approach. ${ }^{6}$ The main objective in neuropathic pain management 


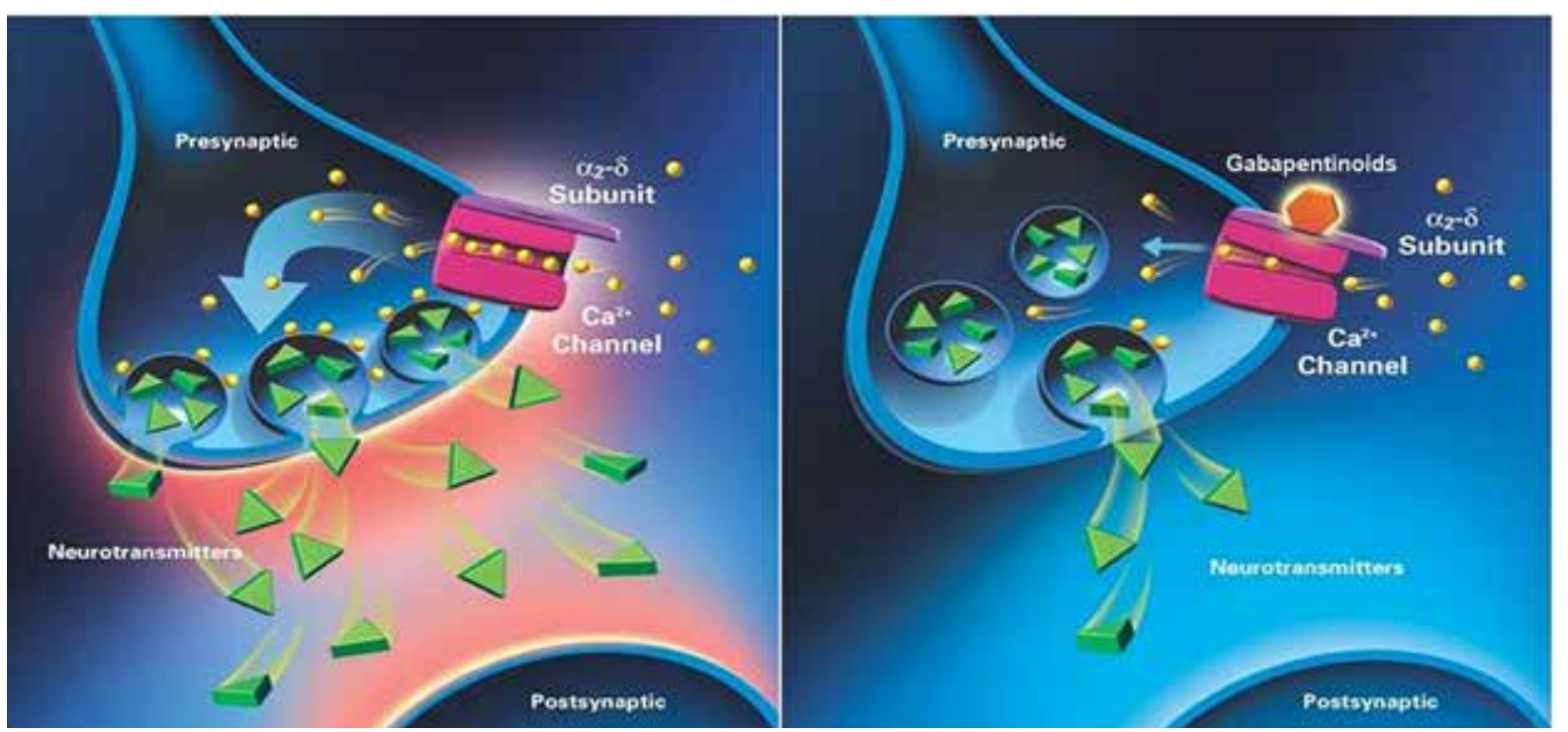

Figure 1: A hyperexcitable neuron associated with neuropathic pain (left pane). Binding of the gabapentinoids to the alpha 2-delta subunit of the calcium channel reduces the neuron's excitability by attenuating neurotransmitter release (Adapted from Shim ${ }^{11}$ ).

$\mathrm{a}_{2}-\delta$ subunit - Alpha 2-delta subunit

$\mathrm{Ca}^{2+}$ channel-Calcium channel

is to decrease spontaneous firing of damaged nerves, and/ or to attenuate ascending hyperalgesic and allodynic signals. The anticonvulsants are theoretically well suited for this, as most exhibit some form of neuronal transmission inhibition via ion channel modulation or inhibitory neurotransmitter modulation. ${ }^{4,6,7}$ However, the exact mechanisms of action in neuropathic pain relief are not fully understood.

Pregabalin and gabapentin - known as the gabapentinoids are both gamma-aminobutyric acid (GABA) analogues. Their structural similarity to GABA facilitates central nervous system penetration, but they do not have any GABAergic activity. ${ }^{8,9}$ The principal mechanism of action is the selective inhibition of the predominantly presynaptic alpha 2-delta subunits of the voltage-gated calcium channels of neurons. ${ }^{10}$ Inhibition of this channel reduces the firing and neurotransmitter release of the neuron (Figure 1).

\section{Place in therapy}

Despite the theoretical rationale for using anticonvulsants in neuropathic pain, the evidence for their use is restricted. A 2013 overview of systematic reviews ${ }^{7}$ - consisting of 10 reviews of 91 studies, including 17955 patients - assessing the anticonvulsants for neuropathic pain, found a wide discrepancy between the different drugs. The review found that only the gabapentinoids (pregabalin and gabapentin) had good quality evidence for their use in painful diabetic neuropathy, postherpetic neuralgia, and central neuropathic pain. ${ }^{7}$ Some low quality evidence was found for the use of carbamazepine in trigeminal neuralgia and painful diabetic neuropathy. Anticonvulsants such as phenytoin, lamotrigine, sodium valproate, and topiramate, as well as the benzodiazepine clonazepam, did not show any evidence of efficacy. ${ }^{7}$ Another systematic review also found that a newer anticonvulsant, levetiracetam, did not have evidence of efficacy in painful neuropathy. ${ }^{12}$ Nonetheless, these drugs may still be considered add-on or second-line therapy in patients unresponsive to first-line pharmacological treatments. ${ }^{4}$

Of note is that pregabalin was found not to be effective for HIV neuropathy in an extensive clinical trial. ${ }^{13}$ The authors postulated that this finding may be due to a high placebo response rate combined with a small treatment effect, or that pregabalin is only effective in a defined subpopulation. The Infectious Diseases Society of America currently recommends gabapentin as first-line therapy for these patients as part of their clinical practice guidelines, ${ }^{14}$ but the recommendation is based on a small study involving only 26 patients. ${ }^{15}$ By contrast, the South African Standard Treatment Guidelines currently recommend carbamazepine or the tricyclic antidepressant, amitriptyline, for HIV-associated neuropathic pain. ${ }^{16}$

The use of carbamazepine may be limited by its adverse effect profile. Common, mild adverse reactions include sedation, nausea, and vomiting, whereas severe reactions involving the skin (Stevens-Johnson syndrome/toxic epidermal necrolysis and other hypersensitivity reactions) and bone marrow (agranulocytosis) are rare. ${ }^{17}$ Hypersensitivity reactions involving the skin have been linked to human leukocyte antigen complex $(H L A)-B^{*} 1502$ in the Chinese population, ${ }^{18}$ and with HLA-A*3101 in the European population. ${ }^{19}$

The gabapentinoids generally exhibit dose-dependent adverse effects, most notably dizziness and sedation. ${ }^{20}$ Pregabalin showed better responses for painful neuropathic conditions at higher dosages, ${ }^{21}$ and it is therefore recommended that pregabalin be started at a low dose, and titrated up to effect. ${ }^{4,22}$ Recent evidence suggests that the gabapentinoids should be prescribed with caution in those receiving opioids. Two studies have found that in patients receiving prescription opioids, concomitant use of gabapentinoids was associated with a significant dose-related increase in the risk of opioid-related mortality. ${ }^{23,24}$ 


\section{Antidepressants}

\section{Mechanism of action}

The main mechanism by which the antidepressants exert their analgesic effect is thought to be by augmenting descending inhibitory pathways in the spinal cord. ${ }^{20,25,26}$ Augmentation is achieved by increasing the concentration of synaptic amine neurotransmitters (mainly serotonin and noradrenaline) by inhibiting the transporters involved in their reuptake into the presynaptic terminal. ${ }^{20,25,26}$ It appears that increasing noradrenaline concentrations in the spinal cord leads to greater analgesic effects compared to serotonin, based on several animal and human studies. ${ }^{27,28}$ In animal models, noradrenaline reuptake inhibition appears to be vital to the attenuation of neuropathic pain. ${ }^{25} \mathrm{~A}$ more recently proposed mechanism of the antidepressants' analgesic effects relate to stimulation of the peripheral adrenergic system. ${ }^{29}$ It has also been suggested that a reciprocal relationship exists between pain and depression: pain may lead to (and worsen) depression, and depression may worsen pain. ${ }^{30-32}$ The antidepressants therefore seem to improve pain in some situations by addressing the underlying depression, including pain perception. ${ }^{30}$ Nevertheless, the antidepressants appear to possess inherent analgesic activity, as evidenced by the observations that they are effective even in non-depressed patients, and that pain relief occurs much sooner than the expected antidepressive effect, and at much lower doses than needed for depression. ${ }^{20}$

Antidepressants with notable serotonergic and noradrenergic reuptake inhibition include the tricyclic antidepressants (TCAs), such as amitriptyline, and the serotonin-noradrenaline reuptake inhibitors (SNRIs), such as duloxetine and venlafaxine (Figure 2).

\section{Place in therapy}

Several pain societies recommend TCA and SNRI antidepressants - as well as the anticonvulsants described above - as first-line pharmacological therapy for neuropathic pain. ${ }^{5}$ While there is a theoretical rationale for considering other noradrenergicallydriven antidepressants, weak evidence or lack of clinical trials have limited the recommendation of such drugs, including bupropion, mianserin, mirtazapine, and reboxetine..$^{26,34-36}$

Current international guidelines ${ }^{5}$ broadly recommend the TCAs and SNRIs for neuropathic pain, but emphasis is placed on the TCAs for postherpetic neuralgia and neuropathic pain of central origin. Second-line treatment options include the atypical opioids (tramadol and tapentadol), strong opioids, and topical analgesics. $^{5}$

In deciding on patient-specific treatment, the choice of firstline therapy generally depends on patient characteristics, the evidence for a specific drug, previous drug experience, and cost. The TCAs have the highest therapeutic efficacy and are generally inexpensive, but their use and dose escalation is limited by adverse effects, such as sedation and anticholinergic effects (commonly dry mouth, constipation, and palpitations). ${ }^{26}$ The SNRIs tend to exhibit less of these adverse effects, ${ }^{20}$ but are not as efficacious in neuropathic pain relief as the $\mathrm{TCAs}^{37}$ and

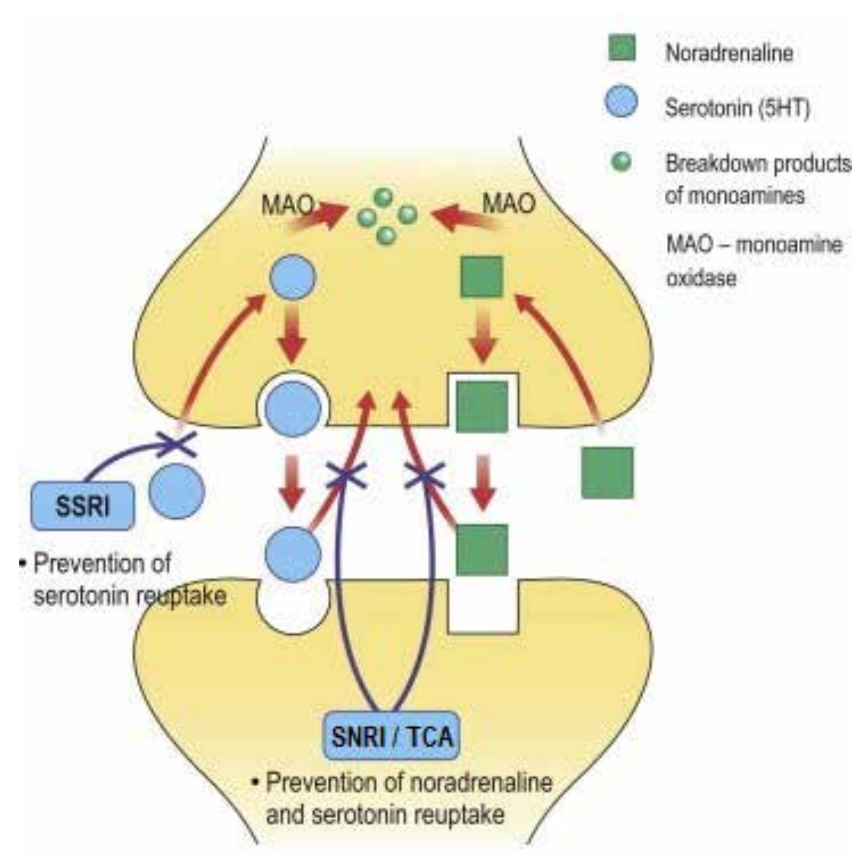

Figure 2: Mechanism of action of the SNRIs, TCAs, and SSRIs (Adapted from Stevens ${ }^{33}$ )

SNRI - Serotonin and noradrenaline reuptake inhibitor

TCA - Tricyclic antidepressant

SSRI - Selective serotonin reuptake inhibitor

are usually more costly. Of note is that the SNRI duloxetine is approved by the American Food and Drug Administration (FDA) for the additional indications of fibromyalgia and, more recently, chronic musculoskeletal pain, including osteoarthritis and chronic lower back pain. ${ }^{38}$ The trials included for the registration of duloxetine for chronic musculoskeletal pain were conducted by the manufacturer and, while a small but significant reduction in pain was seen with duloxetine compared to placebo, one trial found that this difference in response was not sustained beyond 3 months. $^{38}$

To date, the selective serotonin reuptake inhibitors (SSRIs) have shown inconclusive evidence of efficacy in various pain conditions, including neuropathic pain. It may, however, be beneficial for a subset of patients with chronic pain, notably those whose pain is a component of somatic expression of their depression. ${ }^{4}$ Treating the depressive symptoms with SSRIs may then improve or even resolve the associated pain. ${ }^{4,39,40}$

\section{Other medications}

\section{Cannabinoids}

Much controversy exists in the medical and lay literature regarding the synthetic and phytocannabinoids for medical use. The cannabinoids are thought to exert their analgesic effect primarily through the effect of tetrahydrocannabinol (THC) on the endocannabinoid system. ${ }^{41}$ The best evidence for medical efficacy lies with rare forms of childhood epilepsy, namely Lennox-Gastaut ${ }^{42}$ and Dravet $^{43}$ syndromes, and the medical phytocannabinoid, cannabidiol, is FDA approved for these indications. $^{44}$ 
The evidence for the use of cannabinoids for chronic pain is unclear. A 2015 systematic review and meta-analysis found a statistically non-significant reduction in chronic pain, but heterogeneity of indications and type of cannabinoid limited its interpretation. ${ }^{45} \mathrm{~A}$ recent systematic review ${ }^{46}$ assessed the use of synthetic and phytocannabinoids for chronic neuropathic pain. Sixteen studies with 1750 participants were included, and evaluated inhaled herbal, oromucosal sprayed, and synthetic cannabinoids. While the quality of evidence was low and sample sizes small, the review found that the potential benefits of cannabis-based medicine in chronic neuropathic pain might be outweighed by their potential harms. Illustrating this is the finding that the number of patients needed to treat (NNT) for $50 \%$ pain relief was 20 (95\% confidence interval [Cl] 11-100), whereas the number of patients needed to harm (NNH) for the development of a nervous system adverse effect was 3 (95\% Cl 3-6). The NNH for the development of a psychiatric disorder was 10 (95\% Cl 7-16).

\section{Ketamine}

The use of ketamine for chronic pain relief has gained interest in recent years. The analgesic mechanism of ketamine is thought to be mediated by non-competitive N-methyl-D-aspartate (NMDA) receptor antagonism. ${ }^{47}$ Evidence for its use lies with acute postoperative pain relief, with some evidence indicating efficacy in cancer pain. ${ }^{47}$ Ketamine for chronic non-cancer pain does not currently have a strong evidence base, and lack of long-term safety data and effective routes of administration other than intravenous or subcutaneous prohibits its recommendation. . $^{4-49}$ Nevertheless, several pain societies have advocated the use of ketamine in both acute ${ }^{50}$ and chronic ${ }^{51}$ pain. The authors of these guidelines state that while they support ketamine as a viable analgesic option, the recommendations are consensus-based and have low levels of evidence, varying by condition and dose range.

\section{Conclusion}

Chronic pain is complex, and often difficult to manage. This may be due to our current incomplete understanding of chronic pain mechanisms and definitive targets, as well as the mechanisms of action of the currently available drugs. While this review focused on pharmacotherapy, the involvement of a multidisciplinary team and multimodal analgesia is of paramount importance. The evidence for the use of drugs for neuropathic pain presently lies with the gabapentinoids, TCAs, and SNRIs. Topical analgesics, atypical opioids, strong opioids, and SSRIs can be considered for add-on or second-line therapy. Further studies are needed to clearly assess the efficacy and safety of the cannabinoids and ketamine.

\section{References}

1. Merskey H, Bogduk N. IASP Terminology - IASP [Internet]. IASP task force on taxonomy. [cited 2018 Nov 28]. Available from: http://www.iasp-pain.org/ Education/Content.aspx?!temNumber=1698\#Pain

2. Freynhagen R, Parada HA, Calderon-Ospina CA, Chen J, Rakhmawati Emril D, Fernández-Villacorta FJ, et al. Current understanding of the mixed pain concept: a brief narrative review. Curr Med Res Opin [Internet]. 2019 Jan 3 [cited 2019 Apr
3];1-8. Available from: https://www.tandfonline.com/doi/full/10.1080/03007995 .2018.1552042

3. Freynhagen R, Bennett MI. Diagnosis and management of neuropathic pain. BMJ [Internet]. 2009 Aug 12 [cited 2019 Apr 27];339:b3002. Available from: http:// www.ncbi.nlm.nih.gov/pubmed/19675082

4. Rosenquist EW. Overview of the treatment of chronic non-cancer pain [Internet]. Aronson MD, editor. Waltham, MA: UpToDate; 2019 [cited 2019 Apr 27]. Available from: https://www.uptodate.com/contents/ overview-of-the-treatment-of-chronic-non-cancer-pain

5. Cruccu G, Truini A. A review of Neuropathic Pain: From Guidelines to Clinical Practice. Pain Ther [Internet]. 2017 Dec [cited 2019 May 1];6(Suppl 1):35-42. Available from: http://www.ncbi.nlm.nih.gov/pubmed/29178033

6. Tremont-Lukats IW, Megeff C, Backonja M-M. Anticonvulsants for Neuropathic Pain Syndromes. Drugs [Internet]. 2000 Nov [cited 2019 May 1];60(5):1029-52. Available from: http://link.springer.com/10.2165/00003495-200060050-00005

7. Wiffen PJ, Derry S, Moore RA, Aldington D, Cole P, Rice ASC, et al. Antiepileptic drugs for neuropathic pain and fibromyalgia - an overview of Cochrane reviews. Cochrane database Syst Rev [Internet]. 2013 Nov 11 [cited 2019 May 1];2013(11):CD010567. Available from: http://www.ncbi.nlm.nih.gov/ pubmed/24217986

8. Taylor $C P$, Angelotti T, Fauman E. Pharmacology and mechanism of action of pregabalin: The calcium channel $a 2-\delta$ (alpha2-delta) subunit as a target for antiepileptic drug discovery. Epilepsy Res [Internet]. 2007 Feb 1 [cited 2019 May 1];73(2):137-50. Available from: https://www.sciencedirect.com/science/article/ pii/S0920121106003895?via\%3Dihub

9. Taylor CP. Mechanisms of action of gabapentin. Rev Neurol (Paris) [Internet] 1997 [cited 2019 May 1];153 Suppl 1:S39-45. Available from: http://www.ncbi. nlm.nih.gov/pubmed/9686247

10. Sills GS. The mechanisms of action of gabapentin and pregabalin. Curr Opin Pharmacol [Internet]. 2006 Feb 1 [cited 2019 May 1];6(1):108-13. Available from: https://www-sciencedirect-com.ez.sun.ac.za/science/article/pii/ S1471489205001906

11. Shim JH. Clinical Application of a 2- $\delta$ Ligand. Hanyang Med Rev [Internet]. 2011 May 1 [cited 2019 May 4];31(2):55-62. Available from: https://synapse.koreamed. org/DOlx.php?id=10.7599/hmr.2011.31.2.55

12. Wiffen PJ, Derry S, Moore RA, Lunn MPT. Levetiracetam for neuropathic pain in adults. Derry S, editor. Cochrane database Syst Rev [Internet]. 2014 Jul 7 [cited 2019 May 1];(7):CD010943. Available from: http://doi.wiley. com/10.1002/14651858.CD010943.pub2

13. Simpson DM, Rice ASC, Emir B, Landen J, Semel D, Chew ML, et al. A randomized, double-blind, placebo-controlled trial and open-label extension study to evaluate the efficacy and safety of pregabalin in the treatment of neuropathic pain associated with human immunodeficiency virus neuropathy. Pain [Internet]. 2014 Oct [cited 2019 May 1];155(10):1943-54. Available from: http://content.wkhealth.com/linkback/openurl?sid=WKPTLP:landingpage \&an=00006396-201410000-00011

14. Bruce RD, Merlin J, Lum PJ, Ahmed E, Alexander C, Corbett AH, et al. 2017 HIVMA of IDSA Clinical Practice Guideline for the Management of Chronic Pain in Patients Living With HIV. Clin Infect Dis [Internet]. 2017 Oct 30 [cited 2019 May 1];65(10):e1-37. Available from: https://academic.oup.com/cid/article/65/10/ e1/4157299

15. Hahn K, Arendt G, Braun JS, von Giesen H-J, Husstedt IW, Maschke M, et al. A placebo-controlled trial of gabapentin for painful HIV-associated sensory neuropathies. J Neurol [Internet]. 2004 Oct [cited 2019 May 1];251(10):1260-6. Available from: http://link.springer.com/10.1007/s00415-004-0529-6

16. National Department of Health. Standard Treatment Guidelines and Essential Medicines List for South Africa. [Internet]. Pretoria: National Department of Health; 2015 [cited 2019 May 3]. p. 14.23. Available from: http://www.health.gov. za/index.php/component/phocadownload/category/286-hospital-level-adults

17. Novartis Pharmaceuticals Corporation. Tegretol ${ }^{\circledR}$ carbamazepine USP package insert [Internet]. New Jersey; 2009 [cited 2019 May 3]. Available from: https:// www.accessdata.fda.gov/drugsatfda_docs/label/2009/016608s101,018281s048 Ibl.pdf

18. Ferrell PB, MCLeod HL. Carbamazepine, HLA-B*1502 and risk of Stevens-Johnson syndrome and toxic epidermal necrolysis: US FDA recommendations. Pharmacogenomics [Internet]. 2008 Oct 1 [cited 2019 May 3];9(10):1543-6. Available from: https://www.futuremedicine.com/ doi/10.2217/14622416.9.10.1543

19. McCormack M, Alfirevic $A$, Bourgeois $S$, Farrell JJ, Kasperavičiūte $D$, Carrington $M$, et al. HLA-A*3101 and Carbamazepine-Induced Hypersensitivity Reactions in Europeans. N Engl J Med [Internet]. 2011 Mar 24 [cited 2019 May 3];364(12):1134-43. Available from: http://www.nejm.org/doi/abs/10.1056/ NEJMoa1013297 
20. Fornasari D. Pharmacotherapy for Neuropathic Pain: A Review. Pain Ther [Internet]. 2017 Dec [cited 2019 May 3];6(Suppl 1):25-33. Available from: http:// www.ncbi.nlm.nih.gov/pubmed/29178034

21. Derry S, Bell RF, Straube S, Wiffen PJ, Aldington D, Moore RA. Pregabalin for neuropathic pain in adults. Cochrane Database Syst Rev [Internet]. 2019 Jan 23 [cited 2019 May 3];1:CD007076. Available from: http://doi.wiley. com/10.1002/14651858.CD007076.pub3

22. Toth C. Pregabalin: latest safety evidence and clinical implications for the management of neuropathic pain. Ther Adv drug Saf [Internet]. 2014 Feb [cited 2019 May 3];5(1):38-56. Available from: http://www.ncbi.nlm.nih.gov/ pubmed/25083261

23. Gomes T, Greaves S, van den Brink W, Antoniou T, Mamdani MM, Paterson JM, et al. Pregabalin and the Risk for Opioid-Related Death: A Nested Case-Control Study. Ann Intern Med [Internet]. 2018 Nov 20 [cited 2019 May 2];169(10):732-4. Available from: http://annals.org/article.aspx?doi=10.7326/M18-1136

24. Gomes T, Juurlink DN, Antoniou T, Mamdani MM, Paterson JM, van den Brink W. Gabapentin, opioids, and the risk of opioid-related death: A population-based nested case-control study. Tsai AC, editor. PLoS Med [Internet]. 2017 Oct 3 [cited 2019 May 2];14(10):e1002396. Available from: https://dx.plos.org/10.1371/ journal.pmed.1002396

25. Obata H. Analgesic Mechanisms of Antidepressants for Neuropathic Pain. Int J Mol Sci [Internet]. 2017 Nov 21 [cited 2019 Mar 8];18(11):2483. Available from: http://www.ncbi.nlm.nih.gov/pubmed/29160850

26. Kremer M, Salvat E, Muller A, Yalcin I, Barrot M. Antidepressants and gabapentinoids in neuropathic pain: Mechanistic insights. Neuroscience [Internet]. 2016 Dec 3 [cited 2019 May 3];338:183-206. Available from: https:// www-sciencedirect-com.ez.sun.ac.za/science/article/pii/S0306452216302962

27. Mochizucki D. Serotonin and noradrenaline reuptake inhibitors in animal models of pain. Hum Psychopharmacol Clin Exp [Internet]. 2004 Oct 1 [cited 2019 Mar 8];19(S1):S15-9. Available from: http://doi.wiley.com/10.1002/hup.620

28. Webster M. Pharmacologic basis for the use of selective norepinephrine reuptake inhibitors for the treatment of neuropathic pain conditions. Ment Heal Clin [Internet]. 2015 Nov 19 [cited 2019 Mar 8];5(6):284-8. Available from: http:// mhc.cpnp.org/doi/10.9740/mhc.2015.11.284

29. Bohren $Y$, Tessier L-H, Megat S, Petitjean $H$, Hugel $S$, Daniel $D$, et al. Antidepressants suppress neuropathic pain by a peripheral $\beta 2$-adrenoceptor mediated anti-TNFa mechanism. Neurobiol Dis [Internet]. 2013 Dec [cited 2019 May 3];60:39-50. Available from: http://www.ncbi.nlm.nih.gov/ pubmed/23978467

30. Trivedi MH. The link between depression and physical symptoms. Prim Care Companion J Clin Psychiatry [Internet]. 2004 [cited 2019 May 3];6(Suppl 1):12-6. Available from: http://www.ncbi.nlm.nih.gov/pubmed/16001092

31. Holmes A, Christelis N, Arnold C. Depression and chronic pain. Med J Aust [Internet]. 2013 Oct 29 [cited 2019 May 3];199(6):S17-20. Available from: https:// www.mja.com.au/journal/2013/199/6/depression-and-chronic-pain

32. Fishbain DA, Cole B, Lewis JE, Gao J. Does pain interfere with antidepressant depression treatment response and remission in patients with depression and pain? An evidence-based structured review. Pain Med [Internet]. 2014 Sep 1 [cited 2019 May 3];15(9):1522-39. Available from: https://academic.oup.com/ painmedicine/article-lookup/doi/10.1111/pme.12448

33. Stevens L, Rodin I. Psychiatry: an illustrated colour text [Internet]. 2nd ed. Churchill Livingstone; 2011 [cited 2019 May 4]. 26-27 p. Available from: https://www-sciencedirect-com.ez.sun.ac.za/book/9780702033964/ psychiatry\#book-info

34. Baltenberger EP, Buterbaugh WM, Martin BS, Thomas CJ. Review of antidepressants in the treatment of neuropathic pain. Ment Heal Clin [Internet]. 2015 Jul 22 [cited 2019 May 4];5(3):123-33. Available from: http://mhc.cpnp.org/ doi/10.9740/mhc.2015.05.123

35. Micó JA, Ardid D, Berrocoso E, Eschalier A. Antidepressants and pain. Trends Pharmacol Sci [Internet]. 2006 Jul 1 [cited 2019 May 3];27(7):348-54. Available from: https://www-sciencedirect-com.ez.sun.ac.za/science/article/pii/ S0165614706001295\#bib34

36. Mattia C, Paoletti F, Coluzzi F, Boanelli A. New antidepressants in the treatment of neuropathic pain. A review. Minerva Anestesiol [Internet]. 2002 Mar [cited 2019 May 3];68(3):105-14. Available from: http://www.ncbi.nlm.nih.gov/ pubmed/11981519

37. Sindrup SH, Otto M, Finnerup NB, Jensen TS. Antidepressants in the treatment of neuropathic pain. Basic Clin Pharmacol Toxicol [Internet]. 2005 Jun [cited 2019 May 3];96(6):399-409. Available from: http://doi.wiley. com/10.1111/j.1742-7843.2005.pto_96696601.x

38. Food and Drug Administration. Cymbalta (duloxetine hydrochloride) capsules package insert [Internet]. Indianapolis: FDA; 2010 [cited 2019 May 4]. Available from: https://www.accessdata.fda.gov/drugsatfda_docs/label/2010/022516lbl. pdf

39. Patetsos E, Horjales-Araujo E. Treating Chronic Pain with SSRIs: What Do We Know? Pain Res Manag [Internet]. 2016 [cited 2019 May 4];2016:2020915. Available from: http://www.ncbi.nlm.nih.gov/pubmed/27445601

40. Sansone RA, Sansone LA. Pain, pain, go away: antidepressants and pain management. Psychiatry (Edgmont) [Internet]. 2008 Dec [cited 2019 May 4];5(12):16-9. Available from: http://www.ncbi.nlm.nih.gov/pubmed/19724772

41. Zou S, Kumar U. Cannabinoid Receptors and the Endocannabinoid System: Signaling and Function in the Central Nervous System. Int J Mol Sci [Internet] 2018 [cited 2019 May 4];19(3):833. Available from: https://www.ncbi.nlm.nih. gov/pmc/articles/PMC5877694/

42. Devinsky O, Patel AD, Cross JH, Villanueva V, Wirrell EC, Privitera M, et al. Effect of Cannabidiol on Drop Seizures in the Lennox-Gastaut Syndrome. N Engl J Med [Internet]. 2018 May 17 [cited 2019 May 4];378(20):1888-97. Available from: http://www.nejm.org/doi/10.1056/NEJMoa1714631

43. Devinsky O, Cross JH, Laux L, Marsh E, Miller I, Nabbout R, et al. Trial of Cannabidiol for Drug-Resistant Seizures in the Dravet Syndrome. N Engl J Med [Internet]. 2017 May 25 [cited 2019 May 4];376(21):2011-20. Available from: http://www.nejm.org/doi/10.1056/NEJMoa1611618

44. Food and Drug Administration. FDA approves first drug comprised of an active ingredient derived from marijuana to treat rare, severe forms of epilepsy [Internet]. Maryland; 2018 [cited 2019 May 4]. Available from: https://www.fda. gov/news-events/press-announcements/fda-approves-first-drug-comprisedactive-ingredient-derived-marijuana-treat-rare-severe-forms

45. Whiting PF, Wolff RF, Deshpande S, Di Nisio M, Duffy S, Hernandez A V., et al. Cannabinoids for Medical Use. JAMA [Internet]. 2015 Jun 23 [cited 2019 May 4];313(24):2456-73. Available from: http://jama.jamanetwork.com/article. aspx?doi=10.1001/jama.2015.6358

46. Mücke M, Phillips T, Radbruch L, Petzke F, Häuser W. Cannabis-based medicines for chronic neuropathic pain in adults. Cochrane Database Syst Rev [Internet]. 2018 Mar 7 [cited 2019 May 4];3:CD012182. Available from: http://www.ncbi.nlm. nih.gov/pubmed/29513392

47. Bell RF, Kalso EA. Ketamine for pain management. PAIN Reports [Internet]. 2018 [cited 2019 May 4];3(5):e674. Available from: http://insights.ovid.com/crossref ?an $=01938936-201810000-00007$

48. O'Connell NE, Wand BM, McAuley J, Marston L, Moseley GL. Interventions for treating pain and disability in adults with complex regional pain syndromean overview of systematic reviews. Cochrane Database Syst Rev [Internet] 2013 Apr 30 [cited 2019 May 4];4:CD009416. Available from: http://doi.wiley. com/10.1002/14651858.CD009416.pub2

49. Richards BL, Whittle SL, Buchbinder R. Neuromodulators for pain management in rheumatoid arthritis. Cochrane Database Syst Rev [Internet]. 2012 Jan 18 [cited 2019 May 4];(1):CD008921. Available from: http://doi.wiley. com/10.1002/14651858.CD008921.pub2

50. Schwenk ES, Viscusi ER, Buvanendran A, Hurley RW, Wasan AD, Narouze $S$, et al. Consensus Guidelines on the Use of Intravenous Ketamine Infusions for Acute Pain Management From the American Society of Regional Anesthesia and Pain Medicine, the American Academy of Pain Medicine, and the American Society of Anesthesiologists. Reg Anesth Pain Med [Internet]. 2018 Jul 1 [cited 2019 May 4];43(5):456-66. Available from: http://www.ncbi.nlm.nih.gov/pubmed/29870457

51. Cohen SP, Bhatia A, Buvanendran A, Schwenk ES, Wasan AD, Hurley RW, et al. Consensus Guidelines on the Use of Intravenous Ketamine Infusions for Chronic Pain From the American Society of Regional Anesthesia and Pain Medicine, the American Academy of Pain Medicine, and the American Society of Anesthesiologists. Reg Anesth Pain Med [Internet]. 2018 Jul 1 [cited 2019 May 4];43(5):521-46. Available from: http://www.ncbi.nlm.nih.gov/pubmed/29870458 